\title{
Laboreal
}

Volume $9 \mathrm{~N}^{\circ} 1$ | 2013

Varia

\section{Mineração de granito no Município De Vila Pavão/ Es[] : compreender o trabalho para pensar a formação}

Minería en ciudad del granito de la Aldea Del Vila Pavão / Es : comprender el trabajo piensa para la formación

Les rapports sociaux et les conditions de travail dans l'extraction du granit, dans la Municipalité De Vila Pavão, au Espirito Santo/Brésil : comprendre le travail pour penser la formation

Granite Mining in the City of Vila Pavão / Es: understanding the job to think the training

\section{Daniel Handan Triginelli e Daisy Moreira Cunha}

\section{OpenEdition}

\section{Journals}

\section{Edição electrónica}

URL: http://journals.openedition.org/laboreal/5953

DOI: $10.4000 /$ laboreal. 5953

ISSN: 1646-5237

\section{Editora}

Universidade do Porto

\section{Refêrencia eletrónica}

Daniel Handan Triginelli e Daisy Moreira Cunha, « Mineração de granito no Município De Vila Pavão/ Es] : compreender o trabalho para pensar a formação », Laboreal [Online], Volume 9 N01 | 2013, posto online no dia 01 julho 2013, consultado o 04 outubro 2019. URL : http://journals.openedition.org/ laboreal/5953 ; DOI : 10.4000/laboreal.5953

Este documento foi criado de forma automática no dia 4 outubro 2019 


\section{Mineração de granito no Município De Vila Pavão/Es[1] : compreender o trabalho para pensar a formação}

Minería en ciudad del granito de la Aldea Del Vila Pavão / Es : comprender el trabajo piensa para la formación

Les rapports sociaux et les conditions de travail dans l'extraction du granit, dans la Municipalité De Vila Pavão, au Espirito Santo /Brésil : comprendre le travail pour penser la formation

Granite Mining in the City of Vila Pavão / Es: understanding the job to think the training

Daniel Handan Triginelli e Daisy Moreira Cunha

\section{NOTA DO EDITOR}

Manuscrito recebido em : outubro/2011

Aceite após peritagem : março/2013

\section{NOTA DO AUTOR}

Daniel Handan Triginelli - Historiador pelo Centro Universitário de Belo Horizonte, especialista em História e Culturas Políticas pelo Departamento de Pós Graduação em História da Universidade Federal de Minas Gerais (UFMG) e Mestre pelo Programa de Pós-graduação em Educação, Conhecimento e Inclusão Social da Faculdade de Educação (FaE/UFMG). Rua Parajú 25, Vila Patrocínio, Nova Gameleira, Belo Horizonte/Minas Gerais/Brasil, CEP 31510-810.

daniellic.bchistoria@yahoo.com.br 
Daisy Moreira Cunha - Professor Adjunto da Universidade Federal de Minas Gerais ; Programa de Pós-Graduação em Educação FaE/UFMG. Avenida Antônio Caros 6.627, Faculdade de Educação/UFMG, Pampulha, Belo Horizonte/Minas Gerais/Brasil, CEP 31270-901. daisucunha@uol.com.br/daisy-cunha@uol.com.br

\section{Introdução}

1 O interesse em estudar a realidade dos mineiros pavoences se apresentou nos anos de 2007/2008, a partir da participação no "Projeto Piloto da Agenda 21 no Setor Mineral" [2] desenvolvido pelo Núcleo de Estudos Sobre o Trabalho Humano - NESTH/ FAFICH/UFMG em parceria com o Ministério das Minas e Energia. Esse projeto tinha como objetivo construir diagnósticos geológicos e socioeconômicos em seis municípios mineradores brasileiros. A cidade de Vila Pavão foi uma das localidades escolhidas, devido à grande quantidade de granito presente e extraída de seu solo. No decorrer do estudo, realizamos uma pesquisa bibliográfica (teses, dissertações, relatórios de pesquisas, livros, capítulos de livros e artigos) nas bases de dados da Coordenação de Aperfeiçoamento de Pessoal de Nível Superior (CAPES), do Scientific Electronic Library Online (SciELO) e na base de dados do Google Acadêmico. Esta revisão bibliográfica revelou a necessidade de aprofundamento de estudos sobre a realidade dos trabalhadores da extração de granito no município de Vila Pavão, pois muitas questões permaneciam sem resposta : Por que as condições de trabalho são pouco estudadas no setor? Qual o tipo de emprego que é oferecido para essa atividade ? Qual é o tipo de trabalhador que essa atividade exige? Como esse trabalhador se capacita para o trabalho? Qual perfil de trabalhador essa indústria emprega ? Como essa atividade se estabelece no município citado ? Como o Espírito Santo se tornou o maior produtor de rochas ornamentais do país?

2 Esses questionamentos nos trouxeram inquietações e nos colocaram a necessidade de conhecer a realidade desses trabalhadores mais profundamente. Nesse contexto, as relações e condições de trabalho tornaram-se nosso objeto de estudo. Principalmente, devido à realidade relatada pelos trabalhadores, no que diz respeito à ocorrência de acidentes precedidos de mutilação, invalidez e óbito no interior das pedreiras do estado do Espírito Santo, especialmente no município de Vila Pavão. Dessa forma, apresentamos como objetivo geral deste trabalho a compreensão das transformações nas relações e condições de trabalho na atividade de extração de granito em Vila Pavão - ES durante seu processo histórico.

3 Destaca-se que não se poder ignorar a realidade encontrada no município de Vila Pavão e também em todo o estado do Espírito Santo, uma vez que a atividade de mineração se constitui como importante impulsor do Produto Interno Bruto (PIB) capixaba, além de ser um dos principais setores geradores de emprego no estado.

4 Para atender aos propósitos desta pesquisa, investigamos a evolução da extração do mármore e granito na região e realizamos um mapeamento das pedreiras localizadas na cidade estudada, compreendendo o município do ponto de vista socioeconômico e contextualizando-o na cadeia produtiva. Buscamos ainda, numa aproximação sucessiva do trabalho real, descrever e analisar o processo de trabalho, identificando e discutindo as exigências de qualificação feitas aos trabalhadores em função do padrão tecnológico e das normas de segurança no trabalho. 
5 Para alcançar os objetivos traçados pela pesquisa, adotamos a metodologia qualitativa, pois acreditamos que esta permite observar, de maneira mais próxima, as relações que permeiam o objeto de estudo, buscando, junto aos atores, a compreensão do que se pretende entender e, sistemicamente, explicar. Essa metodologia contribuiu para a reflexão e análise do material recolhido sobre as condições e as relações de trabalho nas lavras de granito no município de Vila Pavão/ES. No decorrer do trabalho, recorremos também a estudos bibliográficos e documentais. Além disso, nos utilizamos de dados obtidos através de entrevistas semiestruturadas realizadas com trabalhadores de uma pedreira do município e com atores envolvidos no setor de extração de granito.

Nesta dimensão de nossa análise, confrontamos normas de saúde e segurança prescritas pelos órgãos reguladores da atividade com as situações de trabalho presenciadas. Tal confrontação apontou a precarização das relações e condições de trabalho, possibilitada, inclusive, pelo déficit da aplicação do poder de polícia do Estado em relação ao cumprimento das normas reguladoras da atividade extrativista. Nesse contexto, verificamos o papel determinante da formação no trabalho, associada à experiência dos trabalhadores na construção, no desenvolvimento e na consolidação das atividades extrativistas de mármore e granito.

\section{Trabalho e Relações de Trabalho}

7 Marx (2008) centraliza no trabalho o processo de autoconstituição humana, o elo entre o homem e a natureza na produção de coisas úteis à existência e reprodução do homem. Ele concentra seus estudos no trabalho, como meio de produção e reprodução dos seres humanos em sua constituição histórica no processo de desenvolvimento $\mathrm{e}$ transformação das organizações sociais que permearam e permeiam a história da humanidade.

Antes de tudo, o trabalho é um processo de que participam o homem e a natureza, processo em que o ser humano, com sua própria ação, impulsiona, regula e controla seu intercâmbio material com a natureza. Defronta-se com a natureza como uma de suas forças. Põe em movimento as forças naturais de seu corpo - braços e pernas, cabeça e mãos -, a fim de apropriar-se dos recursos da natureza, imprimindo-lhes forma útil à vida humana. Atuando assim sobre a natureza externa e modificando-a, ao mesmo tempo modifica sua própria natureza. Desenvolve as potencialidades nela adormecidas e submete ao seu domínio o jogo das forças naturais. Não se trata aqui das formas instintivas, animais, do trabalho. Quando o trabalhador chega ao mercado para vender sua força de trabalho, é imensa a distância histórica que medeia entre sua condição e a do homem primitivo com sua forma ainda instintiva do trabalho. Pressupomos o trabalho sob forma exclusiva humana (p. 211).

8 Dentro dessa perspectiva, a história social do trabalho configura-se no acumulo de conhecimentos úteis, na transformação de coisas em estado natural em coisas úteis à utilização e reprodução do homem, que altera, ao mesmo tempo, a si mesmo e ao seu estado social. Essa produção de conhecimento possibilita ao homem desenvolver as condições de produção que constituem o processo de trabalho que impulsiona o processo evolutivo das organizações sociais. Conforme Marx (2008): "Os elementos componentes do processo de trabalho são: 1) a atividade adequada a um fim, isto é o 
próprio trabalhado ; 2) a matéria a que se aplica o trabalho, o objeto de trabalho ; 3 ) os meios de trabalho, o instrumental de trabalho" (p. 212).

Lukács (1979), baseando-se em Marx, explica que o homem, por essência, sempre se reproduziu e continuará a reproduzir-se em qualquer modelo de sociedade através dos frutos obtidos pelo trabalho. Para ambos, essa é a condição na qual o homem sai do estado natural e orgânico para o estado de ser social, alcançado a partir do resultado do trabalho idealizado e adequado de seu esforço. "Através do trabalho, tem lugar uma dupla transformação. Por um lado, o próprio homem que trabalha é transformado pelo seu trabalho; ele atua sobre a natureza exterior e modifica, ao mesmo tempo, a sua própria natureza; (...)" (p. 16). Dessa maneira, o homem passa a formular racionalmente o conhecimento acumulado e a ter maior controle em sua ação sobre a natureza.

10 Com o advento da sociedade capitalista, o trabalho não perde a dimensão acima descrita, continuando a ser o elo entre o homem e a natureza. Lukács (1979) apresenta o paradigma elaborado por Marx que diz :

\begin{abstract}
Mesmo quando o objeto da natureza pareça permanecer imediatamente natural, a sua função de valor-de-uso é já algo qualitativamente novo em relação à natureza ; e, com o pôr socialmente objetivo do valor-de-uso, surge no curso do desenvolvimento social o valor-de-troca, no qual, se considerado isoladamente, desaparece toda objetividade natural : como diz Marx, o que ele possui é uma “objetividade espectral” (p. 19).
\end{abstract}

Estes são efeitos que Gramsci (1976) classificou como novo ciclo civilizatório, a partir da análise do desenvolvimento do capitalismo norte-americano em relação ao europeu e a seus desdobramentos. Para o autor, ao longo da história humana, todas as mudanças de modelo da organização social se deram através de imposições e sofrimentos. Entretanto, segundo o autor, no modelo de organização social capitalista, a repressão se manifesta de maneira mais violenta àqueles que estão sujeitos às novas normas. 0 Americanismo tenta burlar a natureza humana, alterar os sentidos do trabalho, dominar não somente os meios de produção, mas apropriar-se dos saberes históricos dos homens que trabalham, além de organizá-los racionalmente e utilizá-los na automação dos trabalhadores.

Efetivamente, Taylor exprime com cinismo brutal o objetivo da sociedade americana ; desenvolver ao máximo, no trabalhador, as atitudes maquinais e automáticas, romper o velho nexo psicofísico do trabalho profissional qualificado, que exigia uma determinada participação ativa da inteligência, da fantasia, da iniciativa do trabalhador, e reduzir as operações produtivas apenas ao aspecto físico maquinal. Mas, na realidade, não se trata de novidades originais, trata-se somente da fase mais recente de um longo processo que começou com o próprio nascimento do industrialismo, fase apenas que é mais intensa do que as precedentes e manifesta-se sob formas mais brutais, mas que também será superada com a criação de um novo nexo psicofísico de um tipo diferente dos precedentes e, indubitavelmente superior (p. 397).

12 A estrutura de organização social capitalista do trabalho não tira do trabalhador sua condição criadora. Em sua atividade de trabalho, esse trabalhador desenvolve conhecimentos sobre sua atividade que o orientam na ação, desenvolve técnicas que agilizam a produção e modificam os modelos, mesmo que sutilmente. $O$ trabalhador 
nessas circunstâncias constrói modelos, técnicas e estabelece relações sociais que norteiam sua vida produtiva e social. Conforme Brighton Labour Process Group (1991) :

Naturalmente, esta relação entre capital e trabalho não é estática, mas é constantemente reproduzida sob novas condições. É um terreno da luta de classes constantemente renovada. A dominação do capital é reproduzida porque o capital tem tanto poder quanto a necessidade de revolucionar constantemente as forças de produção (p. 24).

13 Nesse sentido, dialogamos com Thompson (2002a) para entendermos o fato de que cada classe trabalhadora tem, em suas manifestações políticas, religiosas, sociais e culturais, diversas variações em termos de posicionamentos e de construção de modelos para entendimento dos paradigmas postos pela organização da sociedade em que estão inseridos. Por essa razão, para conseguir alcançar a dimensão e complexidade dos grupos sociais, o autor afirma que

os valores não são "fatores imponderáveis" que o historiador possa descartar sem receio, apoiando-se no argumento de que, por eles não serem passíveis de mediação, contrários, todas as opiniões a seu respeito teriam a mesma importância. Ao contrário, eles relacionam-se com satisfações humanas e com o curso das mudanças sociais, temas que o historiador tem de considerar, se quiser que a história ocupe lugar entre as ciências humanas significativas (p. 343).

14 Aqui o historiador nos apresenta a importância de se entender o lugar em suas diversas variáveis produzidas pela sociedade que se estuda. Esse esforço reconhece a necessidade de conhecer e valorizar hábitos, costumes, tradições, etc. Thompson (2002a) demonstra que, em qualquer lugar onde ocorram mudanças na estrutura socialpolítica-econômica, existem conflitos e rompimentos de paradigmas ligados à cultura de nossos objetos de estudo ; e que, ao contrário do que se percebe frequentemente, não podemos determinar ou estruturar o regional, específico e peculiar. A história não é cíclica ou retilínea. A história é una em seus aspectos locais, em seus sistemas de valores e na subjetividade e nos interesses de seus sujeitos, justamente pelo fato de a cultura não ser uniforme ou passível de ser definida ou estruturada por leis.

Na realidade, o historiador, ou sociólogo da história, deve se preocupar com duas espécies de juízo de valor. Em primeiro lugar, ele deve considerar os valores realmente partilhados pelos que viveram durante a Revolução Industrial. Cada um dos dois modos de produção em questão está associado a um tipo diferente de comunidade, como um modo de vida característico. Há um conflito entre convenções e noções de satisfação humana alternativas, e existem dados suficientes à disposição de quem desejar estudar as tensões resultantes deste conflito. Em segundo lugar, ele terá de emitir juízos de valor a respeito do processo global da revolução Industrial, do qual nós somos um produto. O nosso envolvimento certamente dificulta a emissão deste juízo. Ainda assim, poderá haver um certo distanciamento, se nos basearmos tanto na crítica "romântica" do industrialismo que se origina de uma parte dessa experiência, quanto no testemunho de tenaz resistência oferecida a ela pelos tecelões urbanos ou rurais, que aderiram rapidamente a uma cultura alternativa. Ao acompanharmos a mudança, descobrimos como chegamos ao que somos hoje. Compreendemos mais claramente o que foi perdido, o que se conservou "subterraneamente" e o que ainda resta por resolver (pp. 343-344). 
Com as colocações acima, Thompson abre um leque de compreensão ligado ao mundo do trabalho e aos seus efeitos históricos (locais e globais), causados pelas sucessivas transformações ao longo do tempo nos locais de ocorrência. A partir do modelo proposto pelo estudioso, encontramos as especificidades locais e os efeitos diretos no modo de vida de cada comunidade onde atividades industriais são implantadas. É possível também entender, a partir dessas situações localizadas, os efeitos em contextos mais amplos, abrindo o campo de compreensão da constituição dos modelos e das formas que adotamos nos cotidianos grupos sociais dos quais fazemos parte. Essa perspectiva abre a possibilidade de compreensão das mudanças e permanências, dos conflitos e aceitações, dos impactos positivos e negativos, enfim. das transformações culturais e seus reflexos no corpo social.

Schwartz (1996) reconhece o trabalho como experiência fundamental no desenvolvimento humano, na organização social e na sociabilidade humana. Se o trabalho é essa experiência fundamental na formação humana, não há sentido em dividir a história em etapas sucessivas de desenvolvimento e/ou mesmo buscar determinar o momento original de aparecimento do mesmo. No entanto, é preciso reconhecer que, se há algo de permanente, que atravessa todos os tempos históricos, há sempre mudanças nas configurações históricas às quais observamos.

(...) ou o trabalho é complicado como o acreditamos: ele acumula a herança de seus sucessivos nascimentos; se não se inventa nada no campo que denominamos "ergológico", é preciso ver o que isso quer dizer: nunca compreenderemos inteiramente esta realidade que articula inextricavelmente o antropológico, o histórico, heranças imemoriais e relações sociais extremamente carregadas de sentido (p. 151).

17 É preciso, portanto, segundo o autor, compreender a relação entre o histórico, o antropológico e as relações sociais carregadas de sentido presente nas atuais sociedades mercantis e de direito. Nestas, se entrecruzam valores dimensionáveis e sem dimensão, perpassando os gestos do trabalho.

18 O autor defende que, se entendemos a atividade trabalho como pura mercadoria e a aceitamos assim, descartamos as possibilidades que a mesma nos coloca de percebermos sua função emancipatória e civilizatória. Schwartz elucida que o trabalho é um dos meios em que homens e mulheres se tornam sociáveis e, dessa maneira, estabelecem relações que vão além da relação mercantil estabelecida pela troca de trabalho/mercadoria pelo dinheiro. 0 autor denomina esse movimento de circulação de valores. Este diz respeito ao conjunto de experiências que são agregadas à formação do sujeito ao longo de sua vida, em seus aspectos psicológico, cultural, social, religioso, político, etc.

19 É preciso reconhecer o fato de que, quando o trabalhador chega a seu ambiente de trabalho, ele é um ser completo, formado por todo um conjunto de valores que orientam sua conduta. $\mathrm{E}$, nesse caso, é preciso ir além e compreender que esses valores se manifestam na sua conduta laboral. É através da soma dos valores incorporados por ele socialmente aos novos valores recebidos em sua atividade produtiva que Schwartz (1996) explicou que :

Toda forma de atividade em qualquer circunstância requer sempre variáveis para serem geridas, em situações históricas sempre em partes singulares, portanto escolhas a serem feitas, arbitragens - às vezes quase inconscientes - 
portanto, o que eu chamo de "uso de si", "uso dramático de si". Simplesmente, em nossa época, é verdade que a forma do trabalho como emprego ou mercadoria é, de um modo geral, quer dizer, nem sempre, o modo mais rico de ativação dentre estes modos "dramáticos" (p. 151).

o "uso de si", conforme o autor, é a dialética historicamente construída na atividade de trabalho. Em todo trabalho, o sujeito executor faz uso de habilidades presentes em seu ser. Além de seus valores, ele incorpora as capacidades que detém. Essa é a dialética presente no trabalho pelo "uso de si", pois estão presentes na atual sociedade capitalista o uso pelo capitalista que compra a força de trabalho, como o uso de si mesmo pelo trabalhador que incorpora "seu si" no que produz. Schwartz (2000) definiu o uso :

(...) quando se diz que o trabalho é uso de si, isto quer dizer que ele é o lugar de um problema, de uma tensão problemática, de um espaço de possíveis sempre a se negociar : há não execução mas uso, e isto supõe um espectro contínuo de modalidades. É o indivíduo no seu ser que é convocado; são, mesmo no inaparente, recursos e capacidades infinitamente mais vastos que os que são explicitados, que a tarefa cotidiana requer, mesmo que este apelo possa ser globalmente esterilizante em relação às virtualidades individuais. Há uma demanda específica e incontornável feita a uma entidade que se supõe de algum modo uma livre disposição de um capital pessoal. Tal é a justificação da palavra "uso" e tal é aqui a forma indiscutível de manifestação de um "sujeito" (p. 41).

E continua, definindo o si, como :

(...) a visão do homem como parte do ser vivo - que constitui a finalidade última de toda redução taylorista - não pode ser a maneira adequada, completa, de ser abordada a questão do sujeito na situação de trabalho. Todo "valor" é social e se inscreve numa história atravessada por antagonismos do qual precisamente o relativo ao trabalho dos homens é um núcleo fundamental. Sob este aspecto que estabelece um laço com a teoria das formas históricas da individualidade, a maneira na qual usos e mal-usos são julgados num espaço que vai da expressão formalizada às regiões do informal e do inconsciente, à espera de serem colocadas em palavras, formalizadas, faz desdobrar um espectro onde o sujeito oscila continuamente entre "si" e "eu", isto é, um centro de experiências e de escolha, que se determina em função de ideias e de símbolos veiculados pelas heranças da história e pelos projetos contraditórios cujo futuro é portador. As microescolhas do uso de si que revelam todo estudo microscópico dos atos de trabalho fazem evidentemente aparecer de qual ponto este "si" se utiliza ele mesmo e, por consequência, se forma como individuo em função de laços, de antagonismos, de potencialidades de vida que as relações sociais engendram na sua própria história (p. 45).

Sendo assim, as situações de trabalho apresentam-se mais complexas. Ou seja, o trabalhador está presente em seus reflexos, seu raciocínio, sua ação, história, suas heranças, seus valores, suas individualidades, relações coletivas, etc. Entrando, dessa maneira, em conflito constante com as atividades prescritas, pois o sujeito é usado ao mesmo tempo em que usa a si mesmo nas relações de trabalho e demais relações sociais.

Todo o trabalho, porque é o lugar de um problema, apela um uso de si. Isto quer dizer que não há simples execução, mas uso, convocação de um 
individuo singular com capacidades bem mais amplas que as enumeradas pela tarefa. Trabalhar coloca em tensão o uso de si requerido pelos outros e o uso de si consentido e comprometido por si mesmo (Schwartz, Adriano \& Abderrahmane, 2008, p. 27).

Dessa forma, o autor ressignifica o trabalho, detectando os valores não mercantis, coloca o trabalho como agente formador, re-humanizando as atividades, através da observação das tarefas humanas que fornecem condições de realização da produção, desconstruindo o paradigma de que o trabalho é mera mercadoria na sociedade de consumo. A execução do ato laboral não consiste apenas em tarefas predefinidas, existe toda uma lógica de organização por aqueles que o executam para se alcançar os objetivos finais.

\section{O Trabalho Real : a formação do trabalhador por si e por outrem}

Na década de 50 do século passado, iniciou-se no estado do Espírito Santo, em especial na região sul do estado, o processo de exploração de mármore e, posteriormente, de granito. Para Abreu e Carvalho (1994), a partir do primeiro investimento em Cachoeiro de Itapemirim, a atividade começou a expandir-se, proporcionando, além da abertura de estradas e da geração de empregos, a entrada de empresários apostando na diversificação promissora da indústria em surgimento, ocupando significativos espaços em cidades do sul do estado, causando impacto e mudanças na estrutura urbana, econômica e social nas localidades em que iam se instalando. Entretanto, Moulin (2006) demonstra o difícil começo da atividade, principalmente devido às condições desfavoráveis na infraestrutura local. Segundo a autora, "A localidade não possuía luz elétrica, água encanada nem outras facilidades características da vida urbana. Tal situação perdurou por muito tempo ainda. Até hoje, as estradas que levam trabalhadores e empresários às pedreiras são de terra batida" (p. 34).

Por outro lado, a atividade alcançava outros atores da sociedade, interessados nas novas possibilidades nos negócios das rochas. Abreu e Carvalho (1994) demonstram as potencialidades que se ramificam das indústrias de pedras capixabas que : "Na medida em que se instalam, vão criando novas expectativas e oportunidades de empregos e riqueza, atraindo, cada vez mais, a atenção das famílias, dos homens de negócio, dos investidores, dos comerciantes e, mais lentamente, das autoridades locais" (p. 8). Em contrapartida, Moulin (2006) coloca que: "A origem dos trabalhadores e de muitos empresários era a mesma : a roça, a lavoura, as dificuldades do campo" (p. 36). Ainda de acordo com a autora, os trabalhadores, antes envolvidos nas atividades do campo, passaram a buscar no novo ramo melhores ganhos. Baptistini (2009) reforça o entendimento da precariedade das condições que antecederam a instauração do ramo de rochas.

Importante observar que, anteriormente a esse período, na década de 50, a economia local era baseada, prioritariamente, no cultivo do café, na cultura de subsistência e na pecuária. Os proprietários de terras produziam com o auxilio dos colonos, a quem era repassada uma pequena quantia do que era produzido, configurando, assim, um cenário marcado pela baixa circulação do dinheiro e por muitas dificuldades financeiras envolvendo patrões e, 
principalmente, os colonos ou meeiros, como também eram conhecidos ( $\mathrm{p}$.

41). muitos proprietários de terra a se encaminharem para a atividade. Nesse movimento, o homem do campo, possuidor de uma porção de terra, na qual se encontra em seu subsolo uma jazida de mármore, passa, de um momento para o outro, de agricultor ou pecuarista a empresário de rochas. Os trabalhadores do campo passam de meeiros a funcionários assalariados de uma atividade para eles desconhecida. Sobre isso Baptistini (2009) explicou que :

Todo esse processo se deu sem nenhuma preparação ou ensinamento, tanto por parte dos empresários como pelos empregados, que aprendiam e sofriam com os seus próprios erros e acertos, o que trouxe sérias consequências para todos os envolvidos. Dentre muitos fatores relacionados à produção naquela época, encontrava-se a falta de capital, inexistência de máquinas e equipamentos para exploração, número insuficiente de trabalhadores, jornadas de trabalho desumanas, além da inexistência de um mínimo de treinamento, conforto e proteção ao trabalhador, como pode ser exemplificado pela falta de botinas e equipamentos de proteção. Não existia sequer conhecimento acerca de leis trabalhistas ou relacionadas à saúde e segurança no trabalho (p. 41). dia a dia, no trabalho!" Em sua visão, o trabalho era aprendido a cada dia, sem mais técnicas prescritas. Eles desenvolviam as técnicas e repassavam aos novos mineiros que se incorporavam à equipe de trabalho. 
$\mathrm{Eu}$, quando eu comecei trabalhar com granito, na mineração, eu comecei praticamente no primeiro dia que eu comecei, eu já não comecei como ajudante. Já comecei direto sendo marteleteiro, né ? Aí de marteleteiro, eu trabalhei um tempo trabalhando em martelo, sendo marteleteiro no caso. E sempre procurando aprender cada vez mais alguma coisa no granito, porque aí, se a pessoa começa como ajudante, se ele tiver interesse, ele passa a ser um marteleteiro. Daí, ele já começa a ser. Ou ele, se tiver uma chance, pode ser um operador de máquina, ou pode ser um encarregado! (T1)

31 Através da fala do T1, podemos perceber a exaltação ao aprendizado por si e por outrem, além da "força de vontade, né? De chegar e pedir à pessoa pra me explicar como que era, e logo aprendi!" o trabalhador, quando questionado se, após seu processo de aprendizagem, ele chegou a realizar algum curso, sua resposta foi não. E disse que o que sabia sobre mineração, aprendeu trabalhando.

32 A formação do Trabalhador 2 (T2), como a de $\mathrm{T} 1$, se deu na prática. Ele conta que começou a trabalhar em pedreiras por volta dos quatorze anos de idade. Nessa época seu pai, trabalhador da empresa, teria conseguido o emprego para o rapaz, que foi contratado para ficar de "bobeira", para ser ajudante.

Eu comecei, meu pai trabalhava em uma empresa, na época eu tinha acabado de completar 14 anos, aí ele conseguiu com o dono da empresa que eu fosse trabalhar lá. Ficar de bobeira lá! Tipo ajudante, né ? Fazer alguma coisinha que precisasse. E rapidinho, por eu já ter sempre ter um tamanho maior, um porte físico maior, eu comecei. Ficava ali, ajudava os caras a arrastar cabo de aço e, na época, eu comecei a pegar no martelete e comecei a furar, entendeu? E assim foi desenvolvendo!

33 Por ter porte físico considerado bom para o desenvolvimento na atividade de marteleteiro, ele iniciou-se na atividade. Porém, ele não contou com nenhuma formação inicial para a função. Como ele mesmo colocou, na época, ele era menor de idade e sua carteira foi assinada como auxiliar de escritório. "Na época não, porque devido eu ser menor. E até minha carteira estava assinada como auxiliar de escritório, entendeu ? E eu tinha minha remuneração, depois que eu estava furando com o martelete, como marteleteiro. Porém, tudo por fora!"

Após essa fase, o trabalhador aprendeu novas funções dentro da pedreira na qual começou a carreira de mineiro. Ele diz que o aprendizado se deu "dentro dali mesmo! Entendeu ?" A partir daí, todo o conhecimento adquirido e construído, "aí, a questão é só praticar mesmo, é você pegar e ir praticando!"

o Trabalhador 3 (T3) lembra-se : "Nossa! o começo foi ruim, foi difícil! Você entrar na pedreira sem saber nada! Nossa Senhora! Assim você vai quebrando a cabeça. Aí eu contei muito com a ajuda dos amigos, que eu tinha muito amigo que já trabalhou. Aí eles foram me ensinando!" Conforme se verifica na fala do mineiro, sua relação com o trabalho se baseia nas relações estabelecidas entre os trabalhadores dentro da pedreira. Conforme T3 coloca, ao iniciar suas atividades, não lhe foram ensinados os procedimentos, não lhe apresentaram o prescrito, não lhe ofereceram formação para aquele serviço. 0 trabalhador chegou sem experiência, sem a dimensão do que era trabalhar em uma pedreira. Entretanto, a aprendizagem aconteceu pela experiência com o outro, pela observação, através de erros nas primeiras tentativas. "Isso! Isso mesmo! A pedreira é sempre assim, chega um novo aqui hoje, eu vou sempre passar pra ele onde que tem perigo, como que funciona, sempre funciona assim !" 

aprendeu a manusear o martelo pneumático e assim, sucessivamente, foi aprendendo todo o serviço e todas as funções dentro da pedreira. Ele se lembra do primeiro dia em que pegou no martelo. $O$ operário valoriza sua conquista pessoal, exalta a solidariedade dos colegas de trabalho e estima a experiência construída coletivamente. Sob recomendação do seu encarregado na época, T3, em um momento de "folga", com o sentimento de curiosidade, aproximou-se de um dos marteleteiros, este logo percebeu sua vontade e lhe entregou a ferramenta.

Eu 'tava' trabalhando de ajudante, eu era ajudante. Aí, eu acabei de abastecer os compressores. Aí, sempre o encarregado falava comigo: "Quando 'cê' tiver, sobrar um tempinho, que 'cê ver' que você 'num' tem serviço pra fazer, encosta nos marteleteiros lá que eles vão te ensinando !” Aí eu acabei de abastecer os compressores, aí eu falei : “Hoje eu vou lá !" E eu era curioso pra aprender a furar, né ? Encostei perto de um marteleteiro lá, o nome dele é até (...). Ele chegou pra mim e falou assim: "Você quer furar ?" Eu falei : “Rapaz, eu não sei pegar nesse trem não!” “Não, pega aí !” Na hora que eu pisei naquele trem, o bicho começou a quicar comigo, quase me derrubou! Ele falou : "Firma, rapaz !" Aí eu fui furando com meia chave, furei uma mina. Aí ele falou: "Não, agora 'cê' tem que olhar o prumo e o esquadro." Aí fui furando, as primeiras 'saiu ruim', mas ruim mesmo! Depois fui praticando. Só que quando a gente é ajudante, quase que a gente 'num' tem tempo de aprender. 'Cê' tem que cumprir primeiro com sua tarefa de ajudante, que é olhar tudo na pedreira.

As falas dos trabalhadores, somadas às fontes bibliográficas que sustentam este estudo, demonstram a inoperância do Estado em fazer cumprir as normas que ele mesmo estabelece para o setor. Ou seja, as normas reguladoras no sentido da formação e capacitação formal dos trabalhadores para este tipo de atividade, assim como a realização de fiscalização para organizar e garantir condições e relações de trabalho adequadas para esse tipo de trabalho. Verificamos que o Estado cumpre de maneira insuficiente o seu papel de fiscalizador, atribuído pelo poder de polícia que lhe é conferido. Nesse sentido, não se pode afirmar que o Estado não tenha atuação fiscalizatória, entretanto, a que tem sido desempenhada até o momento está longe de atender à demanda existente no setor.

\subsection{Sobre o Sentido e o Valor do Trabalho na Extração de Granito Pesquisada}

Com a implantação da indústria de extração de granito no município de Vila Pavão, ocorreram mudanças consideráveis no mercado de trabalho local. O setor gerou uma quantidade significativa de emprego. A nova opção de emprego provocou sensível movimento dos trabalhadores rurais à atividade mineradora, como foi apresentado anteriormente, de maneira semelhante à ocorrida em outras localidades de exploração de rochas ornamentais no Espírito Santo. Em outras palavras, a expansão do setor de mineração motivou os trabalhadores do campo a deixarem sua atividade de origem para tentar obter melhor ganho salarial nas pedreiras. Os antigos trabalhadores do campo escolhem esse caminho acreditando que, dessa forma, conseguiriam garantir mais dignidade e melhor condição para o sustento familiar. Essa é uma das razões 
apontadas por Moulin, Reis \& Weinichi (2001), em explicação para o sentido que foi atribuído ao trabalho na nova indústria.

Uma das enunciações muito presente entre os trabalhadores remete à ideia de trabalho como um modo de sustentar a família, uma garantia de sobrevivência. Trabalhar parece assumir um valor de obrigação, um "fardo pesado" que permite apenas "sobreviver" diante da realidade, uma forma, talvez a única, de se sentir vivo e presente. Seja qual for o trabalho, em quaisquer condições, trabalhar representaria a garantia de vida e de dignidade. Nesse sentido, "é necessário trabalhar", ainda que a vida e a saúde sejam colocadas em risco pelas condições e pela organização do trabalho (p. 234). motivarem os antigos cafeicultores, pecuaristas, etc. a abandonarem sua ocupação de origem. Mesmo nas condições de existências dadas, os autores afirmam que o trabalho é condição para a humanização do homem, pois essa é uma condição inerente à sua condição humana. $\mathrm{O}$ fato de deixarem de ser trabalhadores do campo e passarem a ser operários industriais leva-os a um novo status social, além de ter toda uma relação íntima com a masculinidade deste novo trabalhador. Moulin, Reis \& Weinichi (2001) ressaltaram que :

Tal concepção se, por um lado, reforça a ideia de trabalho como essência humana, que "enobrece o homem", por outro lado, pode estar remetendo a um discurso que tenta legitimar a necessidade de afirmação do lugar social do masculino como provedor, o responsável pelo sustento da família e da prole. Essas duas análises possíveis dão uma dimensão do quanto o sentido do trabalho está atravessado por diversos valores morais e subjetivos construídos social e historicamente (pp. 234-235).

Na perspectiva exposta acima, os autores demonstram que maiores ganhos, oferecidos pela mineração, ocupam um espaço importante na visão dos trabalhadores que migram para o ramo industrial. Entretanto, ao mesmo tempo, fica expresso que não somente esse valor circula entre os trabalhadores nas suas interações cotidianas. 0 trabalho industrial altera sua posição social, novas relações sociais são estabelecidas, novas posturas em relação à vida e ao trabalho são coletivamente construídas, entre outros aspectos. $O$ trabalho aqui não tem valor somente como produtor ou matriz do laço social, como gerador de valores econômicos alcançados na troca do trabalho como mercadoria por salário, ele é uma atividade onde circulam outros valores e saberes oriundos de outras experiências da vida.

41 T1 demonstra as relações de aprendizagem do trabalho a partir da experiência vivida pelos trabalhadores mais antigos, sendo estas fundamentais aos mais novos. Na prática, os trabalhadores veteranos ensinam o trabalho e as funções na pedreira, sendo assim, eles 'explicavam! Porque isso ; aí a pessoa chega dentro 'duma' pedreira pra fazer alguma coisa. Se o pessoal que 'tá lá dentro, que já sabe, 'num' explicar, a pessoa 'num' consegue apanhar, assim, o jeito de trabalho. E trabalhar sozinho não!"

Um dos marteleteiros demonstra o prazer em ensinar, em compartilhar saberes com novos colegas e trocar experiências. Ele lembra-se de quando ainda era ajudante e teve sua primeira oportunidade de utilizar o martelo pneumático. Ele explica que no começo foi complicado dominar a ferramenta em função da trepidação, mas seu "professor", com paciência, o ensinou a dominar a prática. Em pouco tempo o mineiro estava pronto 
para a nova função. Ele diz que gosta de compartilhar o que aprendeu a partir de sua prática com outros colegas e descreve como ensina a um aprendiz sua função dentro da pedreira: "Rapaz, eu faria do mesmo jeito que eu aprendi. Eu ia passar pra ele, entregar o martelo na mão dele devagarzinho, ensinar ele furar uma mina hoje, amanhã fura outra. Se ele tiver boa vontade, em trinta dias ele tá furando pedra já."

o T2 ressalta que o trabalho na pedreira é perigoso, que cada trabalhador deve se preocupar com sua segurança, além de ter o compromisso de trabalhar em equipe e zelar pelos colegas de trabalho e que, no seu entender, constituem uma familia.

Parte de cada um mesmo sua proteção individual ou até mesmo, se tiver mais gente ali, um pelo outro. Onde que tem alguma coisa perigosa: "Oh, fulano, cuidado aí, que tem alguma coisa aí !" Entendeu ? Até porque aqui dentro da empresa, aqui é uma família. A gente passa mais tempo junto aqui com os companheiros de serviço do que com a própria família em casa.

O fato de frequentar outros ambientes que não sejam o de trabalho e com os companheiros da pedreira demonstra uma afinidade que extrapola as relações mercantis tão somente atribuídas ao trabalho. Aqui percebemos e aceitamos o trabalho como sendo mais que a usurpação dos meios de subsistência, consideramos o trabalho um dos elementos centrais da socialização dos homens que circulam e como forma de reconstrução de valores e experiências em seus locais de labor. 0 trabalho, como o T2 demonstra em sua fala, agrega valores, desenvolve saberes, estabelece relações sociais, e isto o leva a considerar a equipe de mineiros uma família. Dentro da pedreira, eles compartilham diversos sentimentos e valores, são capazes de rir, brigar, brincar, se preocuparem, serem cúmplices, desenvolverem técnicas e cuidados uns com os outros, constroem saberes, trocam experiências, trabalham em equipe, aprendem, ensinam, extrapolam as relações do interior da pedreira e as reproduzem e reinventam em outros locais de socialização e vida, etc.

Schwartz (1996) explica que os valores constituídos no trabalho extrapolam os valores econômicos. Para o autor, pensar o trabalho sem mutilá-lo no que ele é, enquanto experiência de nossas sociedades contemporâneas, implica ser capaz de "articular as 'circulações' e as 'barreiras' entre a forma do trabalho como mercadoria e os outros momentos da vida humana" (p. 150). Dessa maneira, o trabalho passa a representar um dos elementos centrais da constituição do social, circulando junto a outros valores que se relacionam e confrontam com sentidos que o trabalho representa para o humano.

\subsection{As contradições nas condições e relações de trabalho na empresa pesquisada}

No desenvolvimento deste estudo, não foi possível ter acesso a um leque de informações satisfatórias em relação à empresa estudada. Mesmo que tenha sido possível a realização de entrevistas com um dos proprietários [4] da pedreira e com um Técnico em Segurança do Trabalho, os mesmos assumiram uma postura resistente em relação à concessão de informações documentais esclarecedoras, no que diz respeito à estrutura, ao planejamento, monitoramento, às relações de trabalho e condições de trabalho.

Conseguimos apurar, via Sindicato dos Trabalhadores na Indústria do Mármore, Granito e Calcário do Espírito Santo (SINDIMÁRMORE), juntamente com as entrevistas 
realizadas com trabalhadores e as observações de campo realizadas nos meses de julho de 2010 e janeiro de 2011, algumas informações que nos ajudam a entender e caracterizar a empresa estudada.

Conforme as informações colhidas em campo, a empresa estudada enquadrava-se, em julho de 2010, na classificação de pequena empresa, tendo esta condição alterada em janeiro de 2011. De acordo com a classificação do Instituto Brasileiro de Geografia e Estatística (IBGE), em estudo realizado no ano de 2006 e publicado em 2008, empresas que mantêm até 9 (nove) funcionários se enquadram como sendo microempresas; as que ocupam de 10 (dez) a 49 (quarenta e nove) trabalhadores mantêm a classificação de pequena.

A pedreira pesquisada, no mês de julho de 2010, contava com 10 (dez) trabalhadores ; já em janeiro de 2011, encontrava-se em atividade com 8 (oito) mineiros operando na lavra. A pedreira está geograficamente localizada na região rural do município de Vila Pavão, região noroeste do Espírito Santo, não se diferindo dos demais empreendimentos da região e da maioria das pedreiras do estado.

Sua atividade está ligada à extração e comercialização de blocos de granito na cor verde pavão. 0 processo de obtenção de blocos se dá a partir de lavra de corpo de rocha solto do maciço rochoso (denominado, pelos atores envolvidos com o setor, de matacão). Os blocos obtidos na pedreira têm como destino final, em sua maioria, o mercado externo. o proprietário da pedreira explica a saída do produto da seguinte forma :

Tem a exportação! Vamos falar assim. 30 \% é interno, interno que a gente fala é aqui mesmo, e aqui de repente se vende e se comercializa essa chapa. $\mathrm{E}$ vamos colocar aí : 70 \% é exportação pra fora do estado e para fora do país. China, Itália, Canadá são os grandes consumidores. China, principalmente.

51 Os trabalhos na pedreira acontecem de segunda a sexta-feira, das $7 \mathrm{H}$ da manhã às $17 \mathrm{H}$ da tarde, com intervalos de uma hora de almoço, das $11 \mathrm{H}$ da manhã às $12 \mathrm{H}$ (meio-dia), e de quinze minutos para o lanche da tarde, que ocorre das $15 \mathrm{H}$ às $15 \mathrm{H} 15$. Porém, de acordo com os trabalhadores, o funcionamento aos sábados é comum, dependendo da demanda de entrega definida a partir da vendagem dos blocos.

É importante ressaltar que a empresa em questão encontra-se desde 14 de dezembro de 2009 sob o Termo de Compromisso de Ajustamento de Conduta (TCAC), em virtude de irregularidades denunciadas e verificadas pelo Ministério Público do Trabalho (MPT). Conforme o documento público oficial, o TCAC, essas irregularidades estão diretamente ligadas a questões que envolvem relações e condições de trabalho.

53 Conforme o acordo (TCAC) firmado entre a empresa e o MPT, o empregador fica obrigado a realizar o pagamento mensal dos trabalhadores até o $5^{\circ}$ dia útil após o vencimento do mês subsequente ; realizar o pagamento conforme prevê a Consolidação das Leis Trabalhistas (CLT) do acerto rescisório nos casos de rescisão contratual nos prazos estipulados por leis; realizar, da maneira prevista em lei, as anotações na carteira de trabalho de seus funcionários, da mesma forma cumprindo o prazo estipulado de 48 (quarenta e oito) horas para a realização da assinatura do documento do contratado; e não realizar anotações de condutas desabonadoras nas carteiras de trabalho dos trabalhadores.

54 O documento coloca como obrigação da empresa a publicação, em lugar visível e de acesso aos funcionários, de uma cópia do TCAC firmado junto ao MPT durante 30 (trinta) dias. Da mesma forma, obriga a instituição a enviar cópia ao sindicato laboral 
no prazo de 10 (dez) dias, ficando o sindicato com a obrigação de informar a Procuradoria do Trabalho sobre o cumprimento da ação legal por parte dos contratantes.

O documento coloca, ainda, que todos os trabalhadores da instituição devem ser cientificados de todo o conteúdo do termo firmado junto ao MPT, comprovado por um abaixo-assinado a ser anexado junto aos autos do acordo no prazo de 30 (trinta) dias. Por fim, a empresa fica obrigada a manter cópia do TCAC no livro de inspeção do trabalho, além de fornecer gratuitamente cópia a seus trabalhadores, sempre que requisitado.

Essas são questões centrais postas pelo documento legal e demonstram problemas tanto no campo estrutural do trabalho como no prático, além de serem as informações mais específicas obtidas sobre a empresa. Esclarecemos aqui a dificuldade posta pelos administradores e pelo proprietário do empreendimento em conceder informações que fossem importantes à pesquisa.

\section{Considerações finais}

A pesquisa realizada em uma pedreira de Vila Pavão/ES demonstra que, ao longo das últimas duas décadas, transformações têm ocorrido no setor de extração de pedras ornamentais no Espírito Santo. Porém, demonstra que estas ainda não são suficientes para estabelecer relações de trabalho menos precarizadas para os trabalhadores que executam a extração de granito no município. Foi possível constatar o não cumprimento das normas prescritas pelo conjunto de leis trabalhistas que regem as relações de trabalho no Brasil, normas que orientam as condições mínimas para a realização da extração de rochas ornamentais no território brasileiro.

Ao realizar a análise e sistematização da bibliografia e das fontes primárias e secundárias estudadas, permaneceu para nós a importância do processo de formação no trabalho dos trabalhadores para a estruturação, o funcionamento e desenvolvimento dessa indústria. A partir dos estudos ligados ao tema e, principalmente, das observações in locus e das entrevistas realizadas com os atores envolvidos nesta atividade, foi possível identificar por quais processos o trabalhador participa da construção e reconstrução das normas e métodos para a realização da extração do granito nas situações de trabalho nas quais se encontram.

Podemos falar também que eles trazem para o processo produtivo suas experiências de vida e trabalho, configuradas em saberes e valores que extrapolam os limites estreitos das situações laborais. É dessa forma que Marx, passando por Gramsci, Thompson e Schwartz, guardadas as diferenças e especificidades de cada um desses autores ao abordar o trabalho em diversos contextos históricos, nos possibilita afirmar que também neste caso específico os trabalhadores produzem e se produzem nessa lida quotidiana.

O referencial teórico que orientou esta pesquisa nos auxilia na compreensão do processo histórico do setor de extração das rochas ornamentais capixabas, especialmente o granito em Vila Pavão. Marx nos orienta no entendimento das transformações provocadas no ambiente natural pela ação humana e, da mesma forma, apresenta a transformação sofrida pelo homem no processo de trabalho, transformando o natural e, consequentemente, promovendo sua socialização. Dentro 
do processo de socialização e construção de formas sociais, Gramsci demonstra as tentativas de modelação dos trabalhadores industriais praticadas pelo sistema capitalista, procurando ofuscar a subjetividade dos homens que trabalham. Thompson incorpora o estudo da cultura na construção das formas sociais e sua relação de resistência e influência no processo coletivo de socialização, em especial a partir do processo de industrialização do trabalho. Por fim, Schwartz nos auxilia a compreender como, mesmo em situações de trabalho nas quais o trabalhador parece completamente subjugado, suas ações são carregadas de sentidos, valores e saberes que os levam de forma direta ou indireta a inventar e reinventar suas formas de trabalho.

61 Esses autores nos instrumentalizaram para compreender a realidade estudada e para evidenciar como os trabalhadores, ao longo do desenvolvimento histórico do setor, criaram, recriaram e recriam técnicas, formas e meios para realizar seu trabalho. Além disso, verificamos que, nas regiões onde a atividade minerária se instalou, ocorreram mudanças substanciais no modo de organização local, econômica, social, cultural e produtiva.

A realidade presenciada em nossas tarefas de observação, registro e entrevistas no ambiente da pedreira pesquisada demonstrou que os trabalhadores aprendem o trabalho por eles desenvolvido no ato do trabalho. É frequente e comum a valorização da vivência social e dos ensinamentos dos mineiros mais antigos do setor aos mais jovens. Não que a prática, os saberes e as experiências não tenham valor. Pelo contrário, defendemos que ela seja o alicerce na organização do trabalho, bem como especificamente da formação, mas entendemos que ela deva ser somada à formação profissional e à capacitação técnica em cursos de formação inicial do trabalhador para a execução de suas tarefas.

Ainda no campo de tensão, é perceptível a insuficiência do Estado como agente regulador e fiscalizador. Conforme os documentos regulatórios, o Estado deveria agir exercendo o poder de polícia, intervindo na formação e capacitação profissional dos trabalhadores, da mesma maneira que deveria ter estruturado o aparelho de fiscalização visando ao cumprimento das normas reguladoras voltadas para o setor.

Nesse sentido, o esforço em compreender as relações e condições de trabalho no setor pesquisado, em especial focando a empresa estudada, proporcionou-nos a compreensão dos aspectos da formação no trabalho dos mineiros, bem como aspectos de sua formação mais geral. Além disso, revelou o papel determinante da formação no trabalho, associada à experiência dos trabalhadores no desenvolvimento do setor mineral.

\section{BIBLIOGRAFIA}

Abreu, A. \& Carvalho, D. (1994). A Força das Pedras : o mármore e o granito no Espírito Santo. Vitória : Pedreiras do Brasil LTDA. 
Baptistini, M. A. (2009). Trabalhadores de Rochas Ornamentais : vida, trabalho, saúde e acesso aos serviços de saúde. Dissertação de Mestrado em Saúde Coletiva, Universidade Federal do Espírito Santo, Vitória/ES.

Brighton Labour Process Group. (1991). O processo de trabalho capitalista. In Tomaz Tadeu da Silva (Org.). Trabalho, Educação e Prática Social. Porto Alegre/RS : Artes Médicas.

Gramsci, A. (1976). Americanismo Fordismo. In Antônio Gramsci. Maquiavel, a política e o Estado Moderno (2a edição, pp. 375-413). Rio de Janeiro/RJ : Civilização Brasileira.

Lukács, G. (1979). Ontologia do Ser Social : Os Princípios Ontológicos Fundamentais de Marx. São Paulo/ SP : Ciências Humanas.

Marx, K. (2008). o Capital : Crítica da Economia Política (25ae edição) ; livro I, volume I. Rio de Janeiro/RJ : Civilização Brasileira.

Moulin, M. G. B. (2006) O lado não polido do mármore e granito : a produção social dos acidentes de trabalho e suas consequências no setor de rochas ornamentais no sul do Estado do Espírito Santo. Tese de Doutorado em Saúde Pública, Escola Nacional de Saúde Pública Sérgio Arouca da Fundação Oswaldo Cruz, Rio de Janeiro.

Moulin, M. G. B., Reis, C. T. \& Weinichi, G. H. (2001). No meio do caminho havia uma pedra Organização do Trabalho e Saúde no Processo de Extração e Beneficiamento de Mármore. In Célia Kiefer, Iracema Fagá e Maria do Rosário Sampaio (Orgs.). Trabalho - Educação - Saúde : um mosaico em múltiplos tons (pp. 221-238). Vitória/ES : FUNDACENTRO.

Thompson, Edward Palmer. (2002a). A Formação da Classe Operária Inglesa II : A maldição de Adão (4a edição). Rio de Janeiro/RJ : Paz e Terra.

Schwartz, Y. (1996). Trabalho e valor. Tempo Social, 8(2), 147-158.

Schwartz, Y. (2000). Trabalho e uso de si. Revista Pro-Posições, 11(2), 34-50.

Schwartz, Y., Adriano, R. \& Abderrahmane, F. (2008). Revisitar a actividade humana para colocar as questões do desenvolvimento : projecto de uma sinergia franco-lusófona. Laboreal, 4(1), 10-22.

\section{NOTAS}

1. O município de Vila Pavão está geograficamente localizado no noroeste do estado do Espírito Santo/ES, situado na região sudeste do Brasil.

2. "Projeto Piloto da Agenda 21 no Setor Mineral", desenvolvido através de parceria realizada entre o Ministério das Minas e Energia e o Núcleo de Estudos Sobre o Trabalho Humano, núcleo este pertencente da Faculdade de Filosofia e Ciências Humanas da Universidade Federal de Minas Gerais - NESTH-FAFICH-UFMG. O projeto possuía, em sua metodologia, tanto instrumentos de análise quantitativa (aplicação de questionários junto a trabalhadores do setor mineral) quanto qualitativa (entrevistas semiestruturadas com representantes do poder público local e representantes da sociedade civil, tais como sindicatos e associações). Como membro da equipe de execução do referido projeto, tive oportunidade de participar da maioria das atividades desenvolvidas no município de Vila Pavão. Alguns dos dados referentes a entrevistas realizadas no município e presentes neste trabalho, apesar de constar dos relatórios do referido projeto, foram completados com observações e levantamento documental do nosso próprio acervo.

3. Em razão de garantir o direito de sigilo firmado com os entrevistados no ato da concordância em conceder entrevistas, reportaremo-nos aos trabalhadores como T1, T2, T3, e T4. Em alguns momentos deste artigo, tratá-los-emos apenas um dos trabalhadores, por entendermos que 
determinadas falas podem evidenciar a identidade ou trazer qualquer possibilidade de identificação do entrevistado. Da mesma maneira, as datas de realização das entrevistas envolvendo trabalhadores não serão expostas, a fim de evitar a identificação e resguardar qualquer possibilidade de ser quebrado o acordo de sigilo absoluto em relação às identidades dos entrevistados.

4. No decorrer da pesquisa, foi possível constatar que a empresa é administrada por quatro sócios. Entretanto, não tivemos acesso a três deles, podendo ter sido realizado o contanto com apenas um. $O$ sócio contatado foi entrevistado pelo pesquisador.

\section{RESUMOS}

O artigo apresenta resultados da pesquisa Relações e Condições de Trabalho na Extração de Granito no Município de Vila Pavão - ES : compreender o trabalho para pensar a formação, cujo objetivo foi compreender as relações/condições de trabalho no setor mineral desvelando aspectos da formação dos trabalhadores em pedreiras de granito. A pesquisa qualitativa foi realizada com base em revisão bibliográfica e documental, observação de postos de trabalho em várias empresas e entrevistas semi-estruturadas com trabalhadores do setor na região norte do Espírito Santo/Brasil. Os resultados apontam a importância estratégica da atividade de trabalho dos mineiros no desenvolvimento do setor mineral na região. O esforço em compreender as relações /condições de trabalho no setor pesquisado, proporcionou-nos conhecer o processo de extração, a formação profissional em serviço e outros aspectos da formação humana dos trabalhadores mineiros.

El documento presenta los resultados de la investigación de las relaciones y condiciones de trabajo en la extracción de granito en el término municipal de Vila Peacock - ES : trabajo entendimiento a pensar en la formación, cuyo objetivo fue comprender las relaciones / condiciones de trabajo en el sector minero revelando aspectos de la formación de los trabajadores en las canteras de granito. La investigación cualitativa se realizó con base en la revisión de la literatura y la observación documental de puestos de trabajo en diferentes empresas y entrevistas semi-estructuradas con los trabajadores del sector en el norte de Espírito Santo / Brasil. Los resultados indican la importancia estratégica de la actividad laboral de los mineros en el desarrollo del sector de la minería en la región. El esfuerzo por entender las relaciones / Condiciones de trabajo en el sector estudiado, nos dio a conocer el proceso de extracción, la formación en cursos de formación y otros aspectos de los mineros humanos.

L'article présente des résultats de la recherche Relations et Conditions de Travail dans l'Extraction de Granit à Vila Pavao - ES : comprendre le travail pour penser la formation, dont l'objectif était de comprendre les liens entre les relations et les conditions de travail dans le secteur minier et certains aspects de la formation des travailleurs dans les carrières de granit. La recherche qualitative a été réalisée sur la base d'une revue bibliographique et documentaire, d'observations d'activités de travail dans plusieurs entreprises et d'entretiens semi-directifs avec des travailleurs du secteur dans la région Nord de l'état d'Espirito Santo/Brésil. Les résultats mettent en évidence l'importance stratégique de l'activité de travail dans le développement du secteur minier de la région. La démarche de compréhension des relations et des conditions de travail dans le secteur étudié, nous a donné des éléments pour connaître le processus 
d'extraction, la formation professionnelle par l'exercice de l'activité et d'autres aspects de la formation humaine des mineurs.

The paper presents the results of the research Working Relations and Conditions in the Granite Extraction in the city of Vila Pavão - ES: understand the work to think about the training, whose objective was to understand the working relations/conditions in the mineral sector, unveiling aspects related to the training of workers in granite quarries. The qualitative research was accomplished through the review of literature and documents, observation of workplaces in several companies and semi-structured interviews with workers of this sector in the northern region of Espírito Santo/Brazil. The results point to the strategic importance of the miners' work activity in the development of the mineral sector in the region. The effort to understand the working relations/conditions in the sector under research provided knowledge about the process of extraction, the vocational training on the job and other aspects regarding the human training of workers as miners.

\section{ÍNDICE}

Keywords: granite extraction, work relationships, working conditions, on-the-job training Palavras-chave: extração de granito, relações de trabalho, condições de trabalho, formação no trabalho

Mots-clés: extraction du granit, relations de travail, conditions de travail, formation professionnelle

Palabras claves: extracción de granito, las relaciones laborales, condiciones de trabajo, la capacitación laboral

\section{AUTORES}

\section{DANIEL HANDAN TRIGINELLI}

Programa de Pós-Graduação em Educação FaE/UFMG, Faculdade de Educação/UFMG, Avenida Antônio Caros 6.627, Pampulha, Belo Horizonte/Minas Gerais/Brasil daniellic.bchistoria@yahoo.com.br

\section{DAISY MOREIRA CUNHA}

Programa de Pós-Graduação em Educação FaE/UFMG, Faculdade de Educação/UFMG, Avenida Antônio Caros 6.627, Pampulha, Belo Horizonte/Minas Gerais/Brasil daisucunha@uol.com.br/daisy-cunha@uol.com.br 